\title{
In silico structure-activity relationshipand virtual screening of monosubstituted doxycycline with pseudomonas aeruginosa lipase
}

\begin{abstract}
Doxycycline(4,5,5,6,12)-4-(dimethylamino)-3,5,10,12,12-pentahydroxy-6-methyl-1,11dioxo-1,4,4a,5,5a,6,11,12a-octahydrotetracene- 2-carboxamide) is a drug used for the treatment of infections caused by bacteria and protozoa. We carried out molecular docking for six analogous structurally diverse (doxycycline) against Pseudomonas aeruginosa lipase using Patchdock and Firedock softwares server. Extensive structure activity relationship work was carried out with these molecules. Physicochemical, lipophilicity, solubility, pharmacokinetics and Lipinski druglikeness of doxycycline and its analogues were evaluated. These molecules were designed by substituting $\mathrm{NH}_{2}$ with $\mathrm{NO}_{2}, \mathrm{CONH}_{2}$, $\mathrm{COOH}, \mathrm{CHO}$ and $\mathrm{OCH}_{3}$ functional groups. The scoring function (empirical binding free energy) was used to estimate the inhibitory activity of protein-ligand complex. The binding energy of doxycycline was $-39.25 \mathrm{kcal} / \mathrm{mol}$. The free binding energies of $\mathrm{NO}_{2}$, $\mathrm{CHO}, \mathrm{CONH}_{2}, \mathrm{COOH}$, and $\mathrm{OCH}_{3}$ analogues of doxycycline were $-43.43,-43.86,-44.97$, -39.40 and $-35.78 \mathrm{Kcal} / \mathrm{mol}$ respectively. All the monosubstituted analogues of doxycycline, except $\mathrm{COOH}$ monosubstituted analogue showed lower values than the non substituted doxycycline. These lower values (more negative values), means that they show better antimicrobial activity than doxycycline. These results clearly indicated that the new substituents may be better antimicrobial agents. Synthesis and pre-clinical studies of these monosubstituted derivatives with Pseudomonas aeruginosa lipase is recommended in order to confirm their new potentials as better antimicrobial agent than the unsubstituted analogue.
\end{abstract}

Keywords: Docking; Doxycycline; Pseudomonas aeruginosa lipase; Scoring function; Solubilit
Volume 5 Issue 3 - 2017

\author{
Ikpeazu OV,' Otuokere IE, ${ }^{2}$ Igwe $\mathrm{KK}^{3}$ \\ 'Department of Biochemistry, Abia State University, Nigeria \\ 2Department of Chemistry, Michael Okpara University of \\ Agriculture, Nigeria \\ Department of Vet Biochemistry and Pharmacology, Michael \\ Okpara University of Agriculture, Nigeria
}

Correspondence: Otuokere IE, Department of Chemistry, Michael Okpara University of Agriculture, Umudike, Nigeria,Tel +234(0)7065297631, Email ifeanyiotuokere@gmail.com

Received: June 01, 2017 | Published: June 27, 2017
Abbreviations: $\mathrm{PDB}$, protein data bank; BBB, blood brain barrier; $\mathrm{NO}_{2}$, nitrogen dioxide; $\mathrm{COOH}$, carboxylic acid

\section{Introduction}

One of the important drugs used for the treatment of infections caused by bacteria and protozoa is deoxycycline. It is indicated for lung infection of bacterial origin, chlamydia, syphilis and cholera. It has also been used in combination with quinine for prevention of malaria. ${ }^{1}$ Doxycycline is a broad spectrum antibiotic belonging to the class of tetracycline which its anti microbial activity is by inhibition of protein biosynthesis. ${ }^{1,2}$ It became an important medication needed in basic health care delivery in man and animals. ${ }^{3}$

Moraxella catarrhalis, Chlamydia pneumoniae, Mycoplasma pneumonia and Brucella melitensis are generally susceptible to doxycycline, while some Mycoplasma hominis, Pseudomonas aeruginosa and Haemophilus spp have developed resistance to varying degrees. ${ }^{4}$ Doxycycline is used in the treatment of respiratory tract infection, ${ }^{5}$ lyme disease, ${ }^{6-10}$ psittacosis, relapsing fever, chancroid, cholera, campylobacter fetus infections, brucellosis, bubonic plague, Rocky mountain spotted fever and ehrlichiosis while being used for prophylaxis and treatment of leptospirosis ${ }^{11}$ and Anthrax. ${ }^{12,13}$ Some Gram-positive bacteria have developed resistance to Doxycycline except Streptococcus pneumonia, Staphylococcus aureus and Bacillus anthracis while some infections caused by Gram-negative bacteria can be treated by Doxycycline such as Shigella species infections, Enterobacter aerogenes infections, Escherichia coli, Actinobacter species infections, Haemophilus influenza infections and Klebsiella species infections. ${ }^{14,15}$ Doxycycline has been successfully used to treat respiratory tract infection, ophthalmic and sexually transmitted diseases. Adverse effects have been seen to include erythematous rash in sun exposed parts of the body which resolves on the discontinuation of the drug. ${ }^{16}$

Interaction of doxycycline with food and drugs containing antacids, dairy products, iron, magnesium and calcium supplements reduces doxycycline absorption and effectiveness ${ }^{17}$ probably due to chelation and an increased gastric $\mathrm{pH}$ making it advisable for doxycycline to be taken on an empty stomach. ${ }^{18}$ Doxycycline is contraindicated during pregnancy, breastfeeding, infancy and childhood stages in humans because it crosses into breastmilk and disrupts bone and tooth development in these stages up to the age of eight years ${ }^{19,20}$ except in the treatment of anthrax where other medications are not effective. ${ }^{14}$ The mechanism of action of the antibacterial effect of tetracyclines relies on disrupting protein translation in bacteria, thereby damaging the ability of microbes to grow and repair; however protein translation is also disrupted in eukaryotic mitochondria impairing metabolism and leading to effects that can confound experimental results..$^{21,22}$

Drugs are observing resistance to microbes due to long use. We are docking the doxycycline with monosubstitutued compounds to check if they will have better activity and probably show no resistance to microbes. The aim for this research is to determine the substituents that will improve the activity of doxycycline as an antibacterial and anti-protozoa drug and recommend these monosubstituted derivatives for synthesis and pre-clinical trials. Doxycycline structural formula is shown in Figure 1. 


\section{Materials and methods}

\section{Protein preparation}

The crystal structure of Pseudomonas aeruginosa lipase, was obtained from the Protein Data Bank, PDB 1ex9 (Figure 2). The protein structure was subjected to a refinement protocol using Molegro molecular viewer. ${ }^{23}$

\section{Designing of structural analogues of doxycycline}

The structure of doxycycline (Figure 1a) was drawn with ACD/ ChemSketch software..$^{24}$ The structural analogues of doxycycline were developed with structural modifications with different substituents The $\mathrm{NH}_{2}$ group of doxycycline was replaced with $\mathrm{CHO}, \mathrm{NO}_{2}, \mathrm{CONH}_{2}$, $\mathrm{COOH}$, and $\mathrm{OCH}_{3}$ analogues. The structures were built with $\mathrm{ACD} /$ ChemSketch software and minimized with Arguslab software. ${ }^{25}$

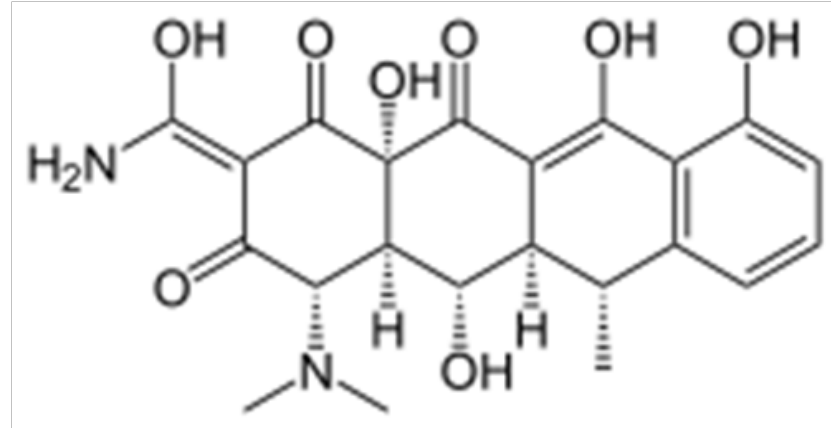

Figure I Doxycycline structural formula.

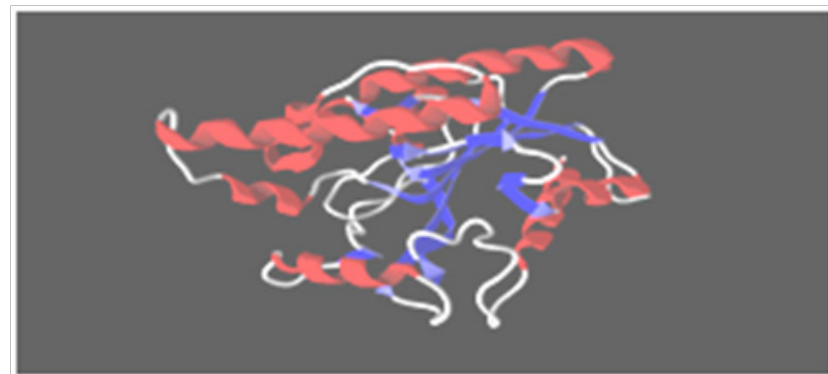

Figure 2 Crystal structure of Pseudomonas aeruginosa lipase PDB lex9.

\section{Molecular docking}

Molecular docking was performed using Patchdock software server. ${ }^{26}$ Patchdock is a molecular docking algorithm based on shape complementarity principles. Refinement was done with Firedock server ${ }^{27,28}$ and processed with Molegro molecular viewer. Physicochemical, lipophilicity, solubility, pharmacokinetics and Lipinski druglikeness of doxycycline and its analogues were determined using SwissADME Server. ${ }^{29}$

\section{Results and discussion}

The Physicochemical, lipophilicity, solubility, pharmacokinetics and Lipinski druglikeness of doxycycline and its analogues are shown in Table 1. Crystal structure of Pseudomonas aeruginosa lipase, is shown in Figure 2, while the docked Doxycycline analogues with Pseudomonas aeruginosa lipase, are presented in Figures 3- 8. The bonding interactions are depicted in Figures $9-14$.

Pseudomonas aeruginosa lipase contains 285 amino acid residues and 112 water molecules. The docking structures of all the compounds showed that they bind in a very similar pattern with the active site of Pseudomonas aeruginosa lipase, as is evident from the superposition of all the 6 analogues in Figures 3-8. The interaction between different substituted analogues with Pseudomonas aeruginosa lipase shows steric interactions with amino acids residues. The calculated free energy of binding of the 6 doxycycline analogues were $-39.25,-43.43,-43.86,-44.97,39.40$ and $-35.78 \mathrm{Kcal} / \mathrm{mol}$ (Table 1). This confirms that the structural modification implemented in this study is significantly related to their activity. Also, this proved the reasonability and reliability of the docking results. It can be seen that substitution of $\mathrm{NH}_{2}$ functional group of doxycycline with $\mathrm{CHO}$, $\mathrm{NO}_{2}, \mathrm{CONH}_{2}$ and $\mathrm{COOH}$ analogues lead to an increase in the binding affinity of modified analogues which is even more intense than that of doxycycline. The binding energy of doxycycline was $-39.25 \mathrm{kcal} / \mathrm{mol}$.

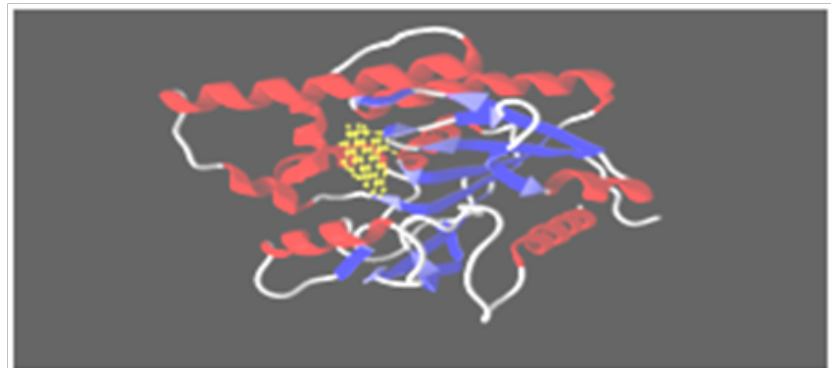

Figure $3 \mathrm{NO}_{2}$ analogue of doxycycline in complex with Pseudomonas aeruginosa lipase.

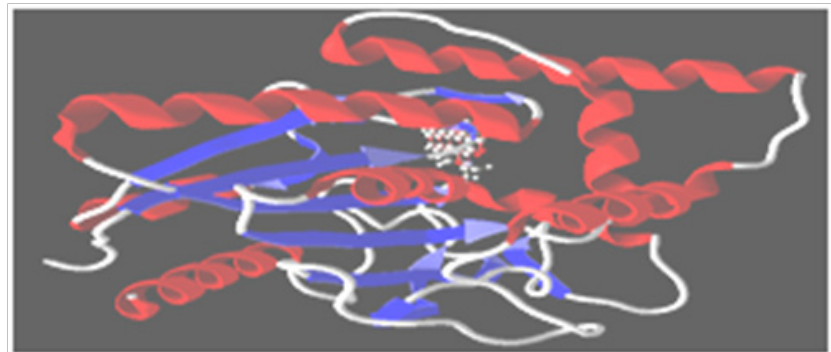

Figure $4 \mathrm{CHO}$ analogue of doxycycline in complex with Pseudomonas aeruginosa lipase.

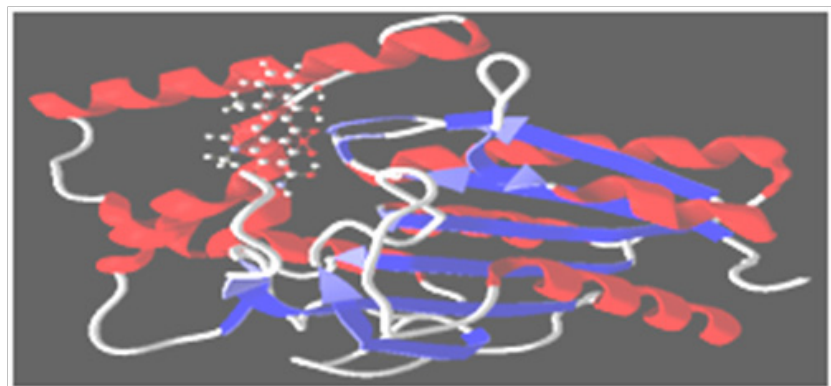

Figure $5 \mathrm{CONH}_{2}$ analogue of doxycycline in complex with Pseudomonas aeruginosa lipase.

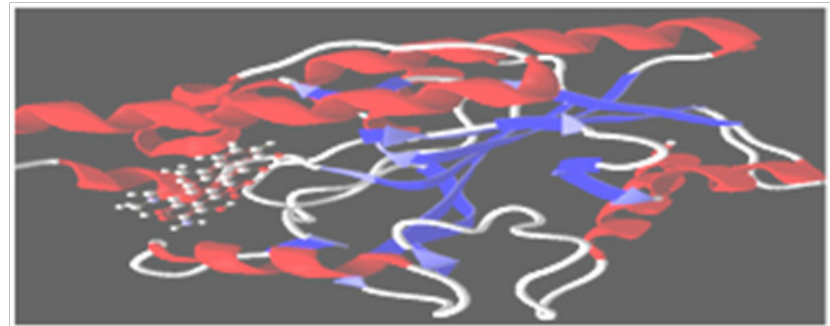

Figure $6 \mathrm{COOH}$ analogue of doxycycline in complex with Pseudomonas aeruginosa lipase. 


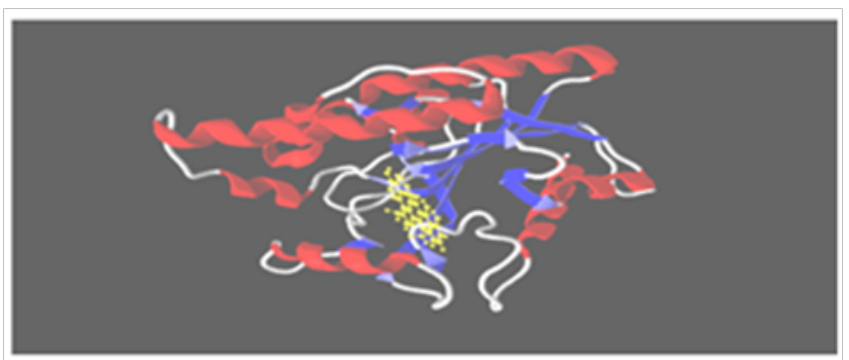

Figure $7 \mathrm{OCH}_{3}$ analogue of doxycycline in complex with Pseudomonas aeruginosa lipase.

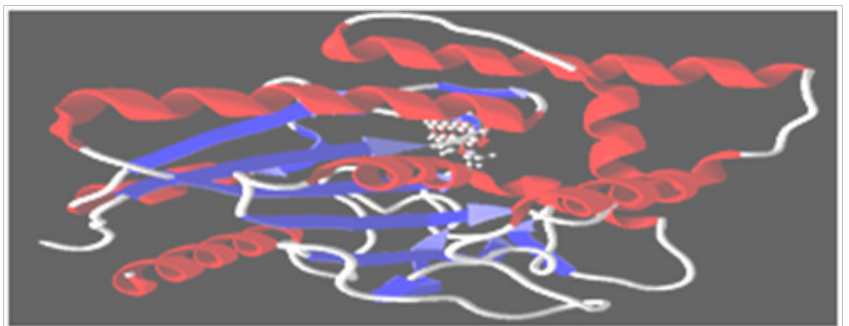

Figure 8 Doxycycline in complex with Pseudomonas aeruginosa lipase.

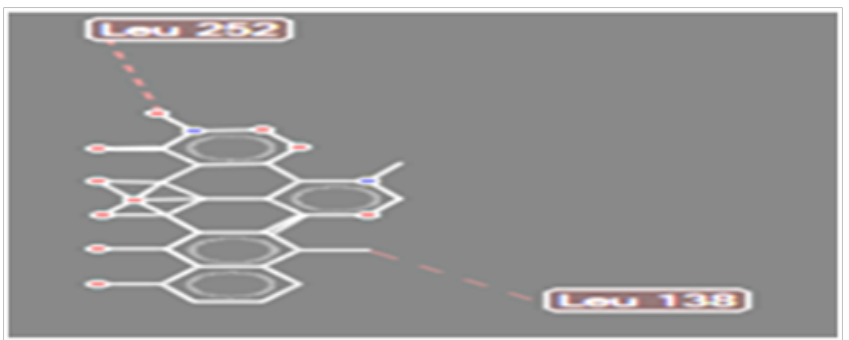

Figure 9 Steric interaction of NO2 doxycycline analogue with amino acids residue of Pseudomonas aeruginosa lipase.

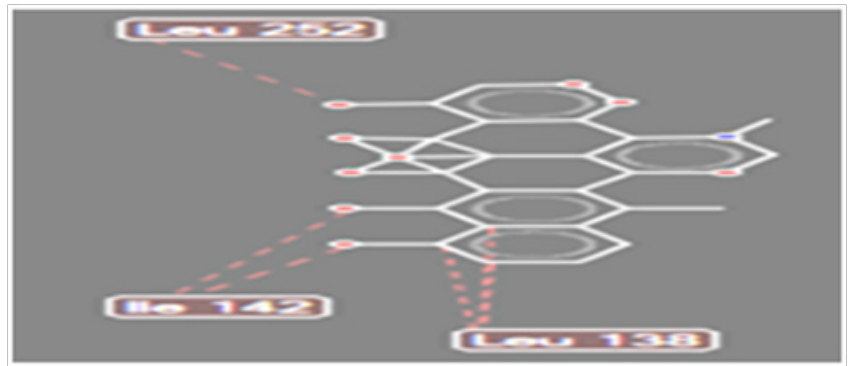

Figure 10 Steric interaction of $\mathrm{CHO}$ doxycycline analogue with amino acids residue of Pseudomonas aeruginosa lipase.

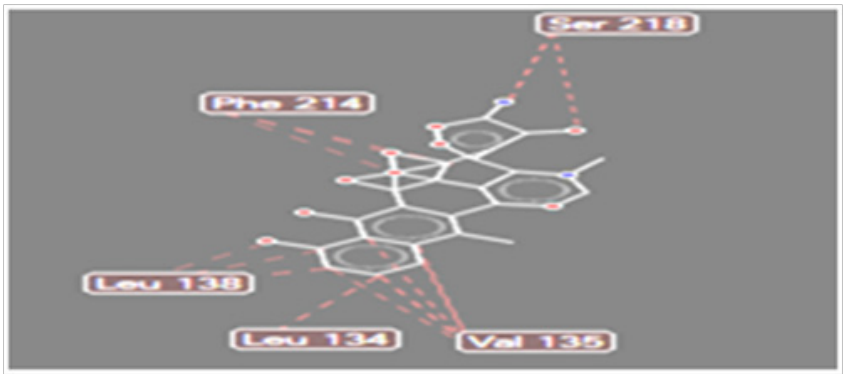

Figure II Steric interaction of $\mathrm{CONH} 2$ doxycycline analogue with amino acids residue of Pseudomonas aeruginosa lipase.

Solubility of compounds in water could improve its biotransformation and elimination as a drug. All the substituted analogues were soluble in water (Table 1). All the substituted derivatives were less than 500 Daltons in mass showing that they can be considered as drug. High lipophilicity which is expressed as Log $P_{\mathrm{o} / \mathrm{w}}$ less than 5 is considered to have drug likeness. All the substituted compounds had $0.28-0.76$ (less than 5) and were most likely to be drugs. In the violation of Lipinski rule, a violation of only one of the 5 rules is acceptable for a drug. All the substituted analogues showed favorable Lipinski rule except the aldehyde [CHO] substituted analogue that violated two rules; less than 5 hydrogen bond donor; less than 10 hydrogen bond acceptors. Therefore the $\mathrm{CHO}$ analogues is not likely to be a drug though it is very soluble in water. Lipinski rule of $5^{30}$ helps in distinguishing between drug like and non-drug like molecules. It predicts high probability of success or failure due to drug likeness for molecules complying with 2 or more of the following rules: Molecular mass less than 500Dalton; High lipophilicity (expressed as $\log P_{\mathrm{o} / \mathrm{w}}$ less than 5); Less than 5 hydrogen bond donors; Less than 10 hydrogen bond acceptors; Molar refractivity should be between 40-130. These filters help in early preclinical development and could help avoid costly late-stage preclinical and clinical failures.

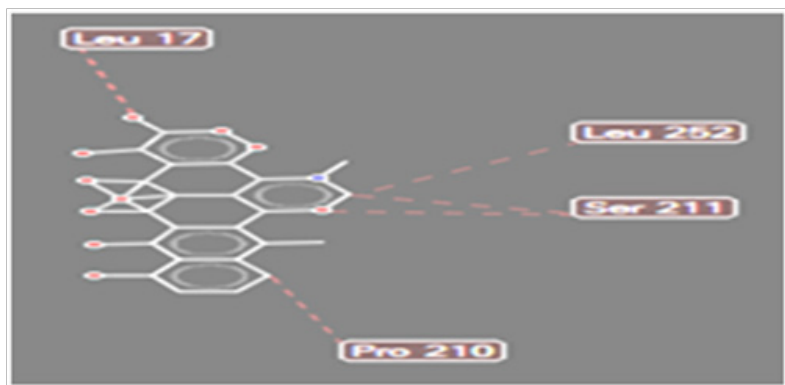

Figure 12 Steric interaction of $\mathrm{COOH}$ doxycycline analogue with amino acids residue of Pseudomonas aeruginosa lipase.

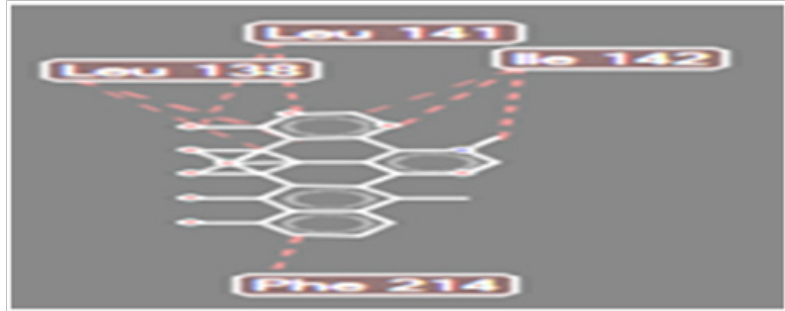

Figure 13 Steric interaction of $\mathrm{OCH} 3$ doxycycline analogue with amino acids residue of Pseudomonas aeruginosa lipase.

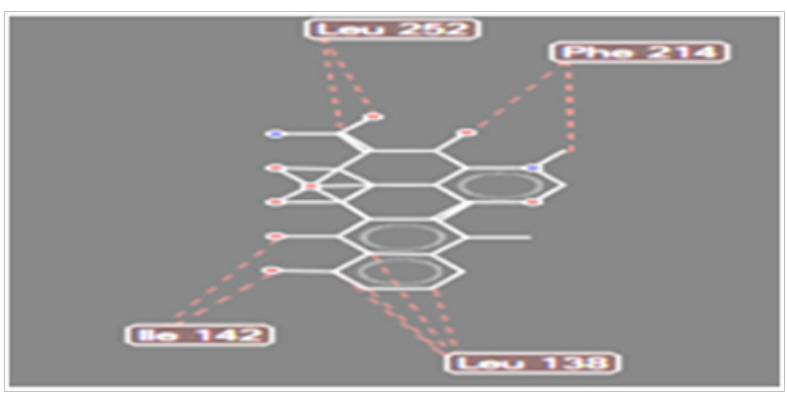

Figure 14 Steric interaction of doxycycline with amino acids residue of Pseudomonas aeruginosa lipase.

Pharmacokinetically, the gastrointestinal drug absorption of all the substituents was low and they could not cross the blood brain barrier (BBB) showing that they cannot cause problem to the brain. For synthetic accessibility, values of 5 to 10 means that the drug could be synthesized. All the substituted analogues could be synthesized in the laboratory because they range between 5.10 and 5.21. 


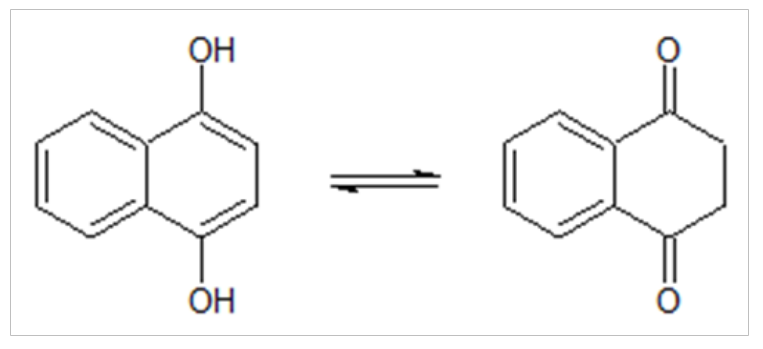

Figure 15 keto-enol tautomerism.

These results clearly indicated that before synthesis and biochemical testing of new analogues one can use molecular docking based methods for qualitative assessment of relative binding affinities for speeding up drug discovery process by eliminating less potent compounds from synthesis. Synthetic studies followed by pre- clinical studies are further recommended.

\section{Conclusion}

We carried out molecular docking for six analogous structurally diverse doxycycline with Pseudomonas aeruginosa lipase using Patchdock and Firedock softwares servers. The binding energy of doxycycline was $-39.25 \mathrm{kcal} / \mathrm{mol}$. The $\mathrm{NO}_{2}, \mathrm{CONH}_{2}$ and $\mathrm{COOH}$ structural analogues were found to be lower (more negative) compared to doxycycline. These lower values, means that they have better functional activity. These results indicated that the new drugs have very good binding affinity towards Pseudomonas aeruginosa lipase like doxycycline. Synthesis and pre-clinical studies of these monosubstituted derivatives with Pseudomonas aeruginosa lipase is recommended.

Table I Physicochemical, lipophilicity, solubility, pharmacokinetics and Lipinski druglikeness of doxycycline and its analogues

\begin{tabular}{|c|c|c|c|c|c|c|}
\hline Parameters & Doxycycline & $\begin{array}{l}\mathrm{NO}_{2} \text { Analogue o } \\
\text { Doxycycline }\end{array}$ & $\begin{array}{l}\mathrm{fCHO} \text { Analogue } \\
\text { of Doxycycline }\end{array}$ & $\begin{array}{l}\mathrm{CONH}_{2} \text { Analogue } \\
\text { of Doxycycline }\end{array}$ & $\begin{array}{l}\text { COOH Analogue } \\
\text { of Doxycycline }\end{array}$ & $\begin{array}{l}\mathrm{OCH}_{3} \text { Analogue of } \\
\text { Doxycycline }\end{array}$ \\
\hline Docking score $\mathrm{Kcal} / \mathrm{mol}$ & -39.25 & -43.43 & -43.86 & -44.97 & -39.4 & -35.78 \\
\hline Num. $\mathrm{H}$-bond acceptors & 9 & 11 & 10 & 10 & 11 & 10 \\
\hline Num. H-bond donors & 6 & 5 & 5 & 6 & 6 & 5 \\
\hline Molar Refractivity & 110.91 & 116.3 & 113.21 & $|15.9|$ & 114.78 & 114.09 \\
\hline $\begin{array}{l}\text { Lipophilicity Consensus } \\
\text { Log Po/w }\end{array}$ & -0.15 & -0.12 & -0.05 & -0.76 & -0.57 & 0.28 \\
\hline Water Solubility Class & Soluble & Soluble & Soluble & Soluble & Very soluble & Soluble \\
\hline Gl absorption & Low & Low & Low & Low & Low & Low \\
\hline BBB permeant & No & No & No & No & No & No \\
\hline P-gp substrate & Yes & Yes & Yes & Yes & No & Yes \\
\hline CYPIA2 inhibitor & No & No & No & No & No & No \\
\hline CYP2CI9 inhibitor & No & No & No & No & No & No \\
\hline CYP2C9 inhibitor & No & Yes & No & No & No & No \\
\hline CYP2D6 inhibitor & No & No & No & No & No & No \\
\hline CYP3A4 inhibitor & No & No & No & No & No & No \\
\hline Lipinski Druglikeness & $\begin{array}{l}\text { Yes; I violation: } \\
\mathrm{H}-\text { don }>5\end{array}$ & $\begin{array}{l}\text { Yes; I violation: } \\
\mathrm{H}-\mathrm{acc}>10\end{array}$ & Yes; 0 violation & $\begin{array}{l}\text { Yes; I violation: } \\
\text { H-don }>5\end{array}$ & $\begin{array}{l}\text { No; } 2 \text { violations: } \\
\mathrm{H} \text {-acc }>10, \mathrm{H} \text {-don }>5\end{array}$ & Yes; 0 violation \\
\hline Synthetic accessibility & 5.15 & 5.28 & 5.1 & 5.2 & 5.15 & 5.21 \\
\hline
\end{tabular}

\section{Acknowledgements}

We are grateful for the research grant from Abia State Government, Nigeria.

\section{Conflicts of Interset}

None.

\section{References}

1. https://www.drugs.com/monograph/doxycycline-calcium.html

2. Nelson ML, Levy SB. The history of the tetracyclines. Ann N Y Acad Sci. 2011;1241:17-32.

3. http://www.who.int/medicines/publications/essentialmedicines/ EML2015_8-May-15.pdf

4. https://www.drugs.com/pro/doxycycline.html

5. Okada T, Morozumi M, Tajima T, et al. Rapid effectiveness of minocycline or doxycycline against macrolide-resistant Mycoplasma pneumoniae infection in a 2011 outbreak among Japanese children. Clin Infect Dis. 2012;55(12):1642-1649.

6. Nadelman RB, Luger SW, Frank E, et al. Comparison of cefuroxime axetil and doxycycline in the treatment of early Lyme disease. Ann Intern Med. 1992;117(4):273-280.
7. Luger SW, Paparone SP, Wormser GP. Comparison of cefuroxime axetil and doxycycline in treatment of patients with early Lyme disease associated with erythema migrans. Antimicrob Agents Chemother. 1995;39(3):661-667.

8. Nadelman RB, J. Nowakowski, Fish JD, "Prophylaxis with single-dose doxycycline for the prevention of Lyme disease after an Ixodes scapularis tick bite. The New England Journal of Medicine. 2011;345(2):79-84.

9. Karlsson M, Hammers-Berggren S, Lindquist L, et al. Comparison of intravenous penicillin $\mathrm{G}$ and oral doxycycline for treatment of Lyme neuroborreliosis. Neurologe. 1994;44(7):1203-1207.

10. https://www.lymedisease.org/lyme-basics/lyme-disease/treatment/

11. http://wwwnc.cdc.gov/travel/yellowbook/2012/chapter-3-infectiousdiseases-related -to-travel/leptospirosis.htm

12. Weinstein RS. Human ehrlichiosis. Am Fam Physician. 1996;54(6):19711976.

13. Karlsson U, Bjöersdorff A, Massung RF, et al. Human granulocytic ehrlichiosis-a clinical case in Scandinavia. Scand $J$ Infect Dis. 1991;33(1):73-74

14. https://www.accessdata.fda.gov/drugsatfda_docs/ label/2012/065055s012lbl.pdf 
15. https://www.accessdata.fda.gov/drugsatfda_docs/ label/2008/065454s000lbl.pdf

16. Kathrine R Tan, Alan J. Magill, et al. Doxycycline for Malaria Chemoprophylaxis and Treatment: Report from the CDC Expert Meeting on Malaria Chemoprophylaxis. The American Journal of Tropical Medicine and Hygiene. 2012;84(4):517-531.

17. https://www.ncbi.nlm.nih.gov/pubmedhealth/ PMHT0010039/?report=details

18. Kshirsagar NA, Ankalesari PS. Effect of food on doxycycline absorption. J Postgrad Med. 1987;33(3):117-119.

19. Mylonas I. Antibiotic chemotherapy during pregnancy and lactation period: aspects for consideration. Arch Gynecol Obstet. 2011;283(1):718.

20. Chun AM, Reed MD, Blume JL. Antibiotics and breast-feeding: a critical review of the literature. Paediatr drugs. 2002;4(12):817-837.

21. Moullan N, Mouchiroud L, Wang X, et al. Tetracyclines Disturb Mitochondrial Function across Eukaryotic Models: A Call for Caution in Biomedical Research. Cell Rep. 2015;10(10):1681-1691.

22. Chatzispyrou IA, Held NM, Mouchiroud L, et al. Tetracycline antibiotics impair mitochondrial function and its experimental use confounds research. Cancer Research. 2015;72(21):4446-4449.
23. http://www.clcbio.com

24. http://www.acdlabs.com

25. http://www.arguslab.com

26. Duhovny D, Nussinov R, Wolfson HJ. Efficient Unbound Docking of Rigid Molecules. International Workshop on Algorithms in Bioinformatics. 2002;2452:185-200.

27. Mashiach E, Schneidman-Duhovny D, Andrusier N, et al. FireDock a webserver for fast interaction refinement in molecular docking. Nucleic Acids Res. 2008;36:229-292.

28. Andrusier N, Nussinov R, Wolfson HJ. FireDock: fast interaction refinement in molecular docking. Proteins. 2007;69(1):139-159.

29. Daina A, Michielin O, Zoete V. A free web tool to evaluate pharmacokinetics, drug-likeness and medicinal chemistry friendliness of small molecules. Sci Rep. 2017;7:42717.

30. Lipinski CA. Lead- and drug-like compounds: the rule-of-five revolution. Drug Discovery Today: Technologies. 2004;1(4):337-341.

31. Anna $\mathrm{KC}$, Bruce $\mathrm{MN}$. Investigations into the Chemistry of Thermodynamically Unstable Species. The Direct Polymerization of Vinyl Alcohol, the Enolic Tautomer of Acetaldehyde. JACS. 1994;116:4073-4074. 